\title{
Os desafios das novas formas de lidar com os resíduos nos territórios inteligentes sob uma perspectiva europeia
}

\author{
Los retos de las nuevas formas \\ de tratamiento de residuos en \\ territorios inteligentes desde \\ una perspectiva europea \\ The challenges of new forms of \\ treating waste in smart territories \\ from a European perspective
}

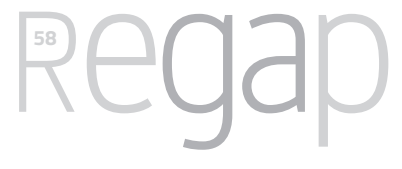

\author{
ROBERTA FERNANDES DE FARIA \\ Doutoranda em Direito na Universidade de Santiago de Compostela \\ Mestre em Direito do Ambiente e advogada \\ fariabeta@gmail.com
}

Recibido: 05/11/2019| Aceptado: 19/12/2019

DOI: https://doi.org/10.36402/10.36402/regap.v1i58.52

\begin{abstract}
Resume: Na intenção de cumprir com os Objetivos de Desenvolvimento Sustentável da ONU, o governo espanhol publicou, em dezembro de 2017, o Plano Nacional de Territórios Inteligentes, apostando na sustentabilidade urbana e melhoria da qualidade de vida dos cidadãos que nas cidades vivem. A Administração Pública deve trabalhar na implementação de um novo modelo de gestão urbana para transformar suas cidades em territórios inteligentes e tratar os principais problemas das cidades tradicionais, incluindo uma nova forma de lidar com os resíduos urbanos e reinventar suas cadeias de suprimento por meio de políticas públicas, regulamentos e incentivos.
\end{abstract}

Palavras-chave: Resíduos, cidades inteligentes, desenvolvimento sustentável, meio ambiente.

Resumen: Con la intención de cumplir con los Objetivos de Desarrollo Sostenible de la ONU, el Gobierno español hizo público, en diciembre de 2017, el Plan Nacional de Territorios Inteligentes, que apuesta por la sostenibilidad urbana y la mejora de la calidad de vida de los ciudadanos en las ciudades donde residen. La Administración pública debe trabajar en la adopción de un nuevo modelo de gestión urbana para transformar sus ciudades en territorios inteligentes y afrontar los principales problemas de las ciudades tradicionales, incluyendo una nueva forma de tratamiento de residuos urbanos y la reinvención de sus cadenas de suministro mediante políticas públicas, reglamentos e incentivos.

Palabras clave: Residuos, ciudades inteligentes, desarrollo sostenible, medio ambiente.

Abstract: With the intention of meeting the UN Sustainable Development Goals, the Spanish government published, in December 2017, the National Plan of Intelligent Territories, focusing on urban sustainability and improving the quality of life of citizens living in cities. Public administration should work on

1 Trabalho realizado no âmbito do projeto de pesquisa: Instrumentos legais para o combate ao despovoamento em áreas rurais (DESPORU), Ref.: RTI2018-099804-A-100. FEDER/Ministério da Ciência, Inovação e Universidades, Agência Estatal de Pesquisa. Governo de Espanha. 
implementing a new urban management model to transform its cities into smart territories and address the main problems of traditional cities, including a new way of dealing with urban waste and reinventing their supply chains through public policies, regulations, and incentives.

Key words: Waste, smart cities, sustainable development, environment.

SUMARIO: 1 Introdução. 2 Os territórios inteligentes. 2.10 desenvolvimento sustentável dos territórios inteligentes. 3 Resíduos. 3.1 Resíduo como recurso. 3.2 Gestão eficiente de resíduos. 3.2.1 Questões políticas e legais. 3.2.2 A tecnologia como facilitadora do serviço público de gestão de resíduos urbanos. 4 Conclusão.

\section{Introdução}

Uma cidade inteligente visa a melhoria da qualidade de vida da população que nela vive e o desempenho sustentável promovido pela administração pública local. Tendo em conta as diversas políticas protetivas do ambiente, é necessário analisar o grande problema da escassez de recursos naturais e o aumento da geração de resíduos sólidos urbanos, bem como os problemas decorrentes da falta de um gerenciamento adequado destes.

A temática dos resíduos é um problema que exige mudanças significativas e este trabalho se propõe a fazer com que este tema, eminentemente urbano, possa receber o tratamento adequado, a partir de uma abordagem interdisciplinar da questão, bem como a feitura de um apanhado das normas e políticas europeias vinculadas ao desenvolvimento sustentável das cidades e a gestão de resíduos sólidos urbanos.

Na União Europeia, tratar enormes quantidades de resíduos, ou melhor evitar que estes sejam gerados, tem sido um dos focos centrais de políticos e legisladores em razão das tendências mundiais, a pressão por um ambiente mais equilibrado e para a consolidação de uma nova realidade socioambiental. A gestão de resíduos sólidos urbanos é um tema de preocupação para os agentes públicos, com impactos diretos na saúde, no ambiente e na qualidade de vida dos cidadãos. Além disso, de acordo com estudo da Organização das Nações Unidas², estima-se que até 50\% dos orçamentos das cidades são gastos na coleta e disposição de resíduos sólidos urbanos, que representa um elevado custo financeiro e ambiental.

Assim, a proposta é abordar as políticas e normas europeias relativas aos resíduos em um contexto de desenvolvimento sustentável para cidades inteligentes.

\section{Os territórios inteligentes}

As cidades precisam gerenciar as suas obrigações (preservação e melhoria do meio ambiente, governança, economia, mobilidade, transporte, serviços públicos, etc.) que tem vindo a ser administradas de forma "inteligente" com o uso de tecnologias

UNITED NATIONS ENVIRONMENT PROGRAMME (UNEP) e UNITED NATIONS INSTITUTE FOR TRAINING AND RESEARCH (UNITAR), Study Guidelines for National Waste Management Strategies: Moving from Challenges to Opportunities. Disponivel em: http://cwm.unitar.org/national-profiles/publications/cw/wm/UNEP_UNITAR_NWMS_English.pdf. 
e infraestruturas que melhoram a prestação dos serviços. Os territórios inteligentes são necessários para tratar os principais problemas das cidades tradicionais, como o tráfego intenso de veículos, o grande fluxo de resíduos, poluição do ar, entre outros. Uma cidade inteligente, em resumo, consiste em melhorar os índices de qualidade de vida dos cidadãos e da gestão pública usando tecnologias emergentes e projetos de soluções urbanas, atraindo investimentos e gerando crescimento econômico, progresso social e prosperidade na cidade ${ }^{3}$. De modo resumido, um território inteligente está relacionado com o desenvolvimento de um novo modelo de cidade com uma base tecnológica que propõe soluções para o sistema ou para melhoria da qualidade de vida dos cidadãos, conectando sociedade, política, setor privado e ambiente.

Além dos 17 Objetivos de Desenvolvimento Sustentáveis (ODS) das Nações Unidas, que são metas globais a serem atingidas até 2030, onde governos, empresas e sociedade em geral estão comprometidos no seu desenvolvimento, uma cidade inteligente segue as normas internacionais ISO 37.120 (modelo de referência para indicadores de serviços e qualidade de vida das cidades, reunindo 17 áreas temáticas4) e ISO 18.091 (que fornece aos governos locais diretrizes para conseguir a classificação qualitativa dos serviços e processos da cidade em 39 atividades essenciais ${ }^{5}$ ). Cidades com melhores

\footnotetext{
REVISTA SMART CITIES. Disponivel em: http://smart-cities.pt/revista-smart-cities/.
}

4 1. Economia; 2. Educação; 3. Energia; 4. Meio Ambiente; 5. Finanças; 6. Incêndio e Respostas a Emergências; 7. Governo; 8. Saúde; 9. Lazer; 10. Segurança; 11. Habitação; 12. Gestão de Resíduos Sólidos; 13. Telecomunicações e Inovação; 14. Transporte; 15. Planejamento Urbano; 16. Águas Residuais; 17. Água e Saneamento.

5 Essa norma internacional promove a adoção de uma abordagem de processo para o desenvolvimento, implantação e melhoria contínua de um sistema de gestão da qualidade para melhorar a satisfação dos clientes a partir de suas necessidades. A norma aborda os seguintes aspectos:

Desenvolvimento institucional para um bom governo

Governo responsável, planejado e organizado com um sistema de gestão integrado de qualidade;

Associado, solidário e conectado;

Competência e continuidade dos serviços públicos;

Engajamento da comunidade nas políticas públicas e programas;

Responsabilidade fiscal;

Promoção da proteção civil e serviços de emergência;

Uso sistemático das tecnologias da informação e comunicação (TIC);

Marco legal vigente e atualizado;

O Estado de direito prevalece no território do governo local;

Transparência e com acesso a informações com integridade e responsabilidade social;

Gestão financeira saudável;

Seguro e consciente da segurança.

Desenvolvimento econômico sustentável

Promoção de alternativas econômicas inovadoras;

Promoção de oportunidades de trabalho decente;

Responsabilidade pela segurança alimentar;

Promoção para a formação de locais de trabalho;

Promoção do turismo;

Responsável pela mobilidade sustentável, rotas de comunicação e interconexões:

Promoção do desenvolvimento econômico primário;

Promoção do desenvolvimento da indústria, comércio e serviços.

Desenvolvimento social inclusivo

Prestação de serviços públicos;

Promoção dos esportes, recreação e desenvolvimento do setor social;

Políticas sociais para incluir as necessidades da população indígena;

Promoção da igualdade de gênero;

Responsável por setores de risco e vulneráveis da população;

Promoção da saúde pública;

Promoção da educação básica de qualidade;

Promoção da moradia digna; 
indicadores de inovação, gestão pública, infraestrutura, educação e sustentabilidades atraem mais investimentos, empresas e negócios.

O impulsionamento de um meio urbano otimizado é importante para a sustentabilidade da economia e do ambiente, transformando o espaço urbano num lugar inovador, funcional e eficiente. Segundo a Comissão Europeia ${ }^{6}$, uma cidade inteligente vai além do uso de tecnologias de informação e comunicação, significando, também, redes de transporte urbano mais inteligentes, instalações aprimoradas de abastecimento de água e eliminação de resíduos e maneiras mais eficientes de iluminar e aquecer edifícios, além de uma administração da cidade mais interativa e responsiva, espaços públicos mais seguros e atendimento às necessidades do envelhecimento da população. O Plano Espanhol de Territórios Inteligentes muito bem delineia os objetivos de construir soluções eficientes para o equilíbrio ambiental (uso racional dos recursos como água e energia e tratamento de resíduos) e melhoria dos serviços públicos (educação, saúde, transporte).

\subsection{O desenvolvimento sustentável dos territórios inteligentes}

A maior parte da população concentra-se nas cidades em razão da dinamização das atividades económicas, maior oferta de emprego e inovação. Entretanto, são nas cidades onde mais se verificam problemas ambientais com graves consequências para a qualidade de vida dos seus cidadãos.

No passado, a preocupação das cidades era no investimento nas infraestruturas de diversas escalas, como estradas, serviços essenciais de água, energia e saneamento. Terminado este ciclo, ganhou importância aprofundar o conhecimento dos recursos territoriais existentes e aprender a geri-los de modo mais eficiente e integrado, promovendo a sua adaptação face à crescente exposição das dinâmicas da globalização e às pressões externas e prosseguindo um modelo de desenvolvimento territorial mais sustentável. Assim, surge a necessidade de um território sustentável, ou seja, uma cidade que reforce o modelo de desenvolvimento urbano que promova a eficiência dos seus subsistemas (energia, mobilidade, água e resíduos) e melhore a capacidade de resposta aos riscos e aos impactos, nomeadamente os relacionados com as alterações climáticas 7 . A tecnologia tem mudado o mundo, o mercado e até a forma de

Promoção da educação cívica e da cultura social responsável;

Promoção da preservação do patrimônio cultural e histórico;

Responsabilidade pelo combate à pobreza.

Desenvolvimento ambiental sustentável

Cuidados com a qualidade do ar;

Limpeza e responsabilidade pelos resíduos;

Cuidado com a imagem circundante;

Cuidado e responsabilidade pelos recursos naturais;

Sistema eficaz de gestão de terras;

Cuidado e responsabilidade pela água;

Cuidados e responsabilidade pelo solo;

Promoção da educação ambiental;

6 COMISSÃO EUROPEIA. Disponivel em: http://ec.europa.eu/eip/smartcities/.

7 GOVERNO PORTUGUÊS, Resolução do Conselho de Ministros n. 61/2015 de 11 de agosto. Disponivel em: https://dre.pt/ application/file/69977523. 
gestão das empresas e das cidades, o que impacta, consequentemente, na qualidade de vida das pessoas ${ }^{8}$.

A busca e criação de cidades inteligentes e sustentáveis estão no topo da agenda pública sobre planejamento e governança urbana, sendo certo que o planeamento sustentável das cidades é importante para atrair investimentos e impulsionar o desenvolvimento econômico e social das comunidades.

O 7. ${ }^{\circ}$ Programa Geral de Ação da União para 2020 em matéria de ambiente, que orientará a política ambiental europeia até 2020 (Decisão n. 1386/2013/UE, do Parlamento Europeu e do Conselho de 20 de novembro de $2013^{9}$ ), tem como $8^{\circ}$ objetivo ajudar as cidades a tornarem-se mais sustentáveis. Segundo dados da Comissão Europeia ${ }^{10}$, a Europa é densamente povoada e até 2020 oitenta por cento dos seus cidadãos viverão, provavelmente, numa cidade, ou próximos de uma. Sendo assim, as cidades, grande parte das vezes, partilham um conjunto comum de problemas, como baixa qualidade do ar, níveis elevados de ruído, emissões de gases com efeito de estufa, escassez de água e resíduos e, por esta razão, o plano europeu citado apoia e promove a inovação e a partilha das melhores práticas nas cidades com o objetivo de assegurar que até 2020, a maioria das cidades da União Europeia estão a aplicar políticas para o planeamento e projeto urbano sustentáveis.

As cidades podem ser definidas como ecossistemas complexos onde diferentes atores, com interesses diversos, são obrigados a colaborar para garantir um ambiente sustentável e uma qualidade de vida adequada ${ }^{11}$. Deste modo, uma cidade inteligente sustentável pode ser considerada como uma cidade que usa tecnologias da informação e comunicação para aumentar a qualidade de vida dos seus habitantes, contribuindo para um desenvolvimento sustentável.

A urbanização, em si, cria um ecossistema urbano com características que alteram o equilíbrio ambiental, tais como: a alta densidade demográfica; uma relação desproporcional entre ambiente constituído e ambiente natural com significativa alteração da diversidade biológica nativa; importação de energia para manter o funcionamento do sistema; um elevado número de resíduos; poluição do ar, entre outras ${ }^{12}$. A ONU ${ }^{13}$ já alertou para este problema, tanto que incluiu como metas dos ODS 11 (cidades e comunidades sustentáveis) temas intrinsecamente relacionados à urbanização, como

8 MACENA, J. P., "Munícipios 4.0 aborda tecnologias que proporcionam melhorias em serviços públicos", Agência Sebrae de Notícias, Alagoas, 2019. Disponivel em: http://www.al.agenciasebrae.com.br/sites/asn/uf/AL/municipios-40-aborda-tecnologias-que-proporcionam-melhorias-em-servicos-publicos,71a2d13eb23fc610VgnVCM1000004c00210aRCRD.

9 Decisão n. 1386/2013/UE do Parlamento Europeu e do Conselho de 20 de novembro de 2013 sobre um programa geral de ação ambiental da União para 2020 "Viver bem, dentro dos limites do nosso planeta". Disponível em: https://eur-lex.europa. eu/legal-content/EN/TXT/?uri=CELEX:32013D1386.

10 COMISSÃO EUROPEIA, 70 Programa de ação para o Ambiente da União Europeia para 2020 em matéria de ambiente: "Viver bem, dentro dos limites do nosso planeta". Disponivel em: https://ec.europa.eu/environment/pubs/pdf/factsheets/7eap/ pt.pdf.

11 CAPDEVILA, J. e ZARLENGA, M.I., "Smart city or smart citizens? The Barcelona case", Journal of Strategy and Management, $\mathrm{n}$. 8(3), 2015, pp. 266-282. Disponivel em: https://www.researchgate.net/publication/277180909_Smart_City_or_smart_ citizens_The_Barcelona_case.

12 PHILIPPI, JR.A. e MALHEIROS, T.F., "Saneamento e saúde pública: integrando Homem e Ambiente", Alves, A.C. e Philippi, JR.A. (eds.), Curso Interdisciplinar de Direito Ambiental, Manole, São Paulo, 2005, p. 5.

13 ORGANIZAÇÃO DAS NAÇÕES UNIDAS. Disponivel em: http://www.agenda2030.org.br/ods/11/. 
a gestão de resíduos sólidos e saneamento de modo a reduzir o impacto ambiental. Neste sentido, surge a preocupação governamental de reduzir os aglomerados urbanos na intenção de minimizar os impactos negativos desta grande urbanização, como é o caso do Plano Nacional de Territórios Inteligentes, do governo espanhol.

Constituir-se uma cidade sustentável inteligente requer ultrapassar alguns desafios, uma vez que os impactos negativos da urbanização e o consumismo desenfreado está a sobrecarregar os recursos naturais finitos disponíveis.

Os governos dos municípios são agentes indispensáveis para a implementação de decisões e acordos ambientais internacionais, tendo em vista que a implementação de tais acordos frequentemente se dá no âmbito das cidades, e a forma como as cidades são planejadas e governadas influencia, significativamente, a dimensão dos impactos diretos e indiretos sobre o meio ambiente ${ }^{14}$. O Plano Nacional de Territórios Inteligentes estabelece que a prestação de serviços públicos busca resolver ou antecipar problemas, mas isso não significa que a provisão deles implique a resolução do problema. Se a política for mal projetada, o problema não deixará de existir, mesmo que o serviço seja prestado perfeitamente. Neste mesmo diploma, é entendido que não basta avaliar se o serviço é prestado ou se seguiu as regras e procedimentos padrões, uma vez que deve ser verificado se o problema foi mitigado ou se ajudou a melhorar, objetivamente, a qualidade de vida dos cidadãos que se beneficiaram da política ou do serviço público prestado.

A União Europeia, em matéria de ambiente urbano, incentiva as cidades a aplicarem políticas de planeamento e ordenamento urbano sustentáveis. Entre estas políticas, incluem questões de mobilidade urbana, edifícios sustentáveis, eficiência energética e conservação da biodiversidade urbana ${ }^{15}$

É certo que as zonas urbanas colocam desafios específicos em termos de ambiente e saúde humana, mas também oferecem oportunidades para utilizar os recursos de forma mais eficiente e é neste sentido que a União Europeia incentiva os municípios a tornarem-se mais sustentáveis através de iniciativas como o prémio "Capital Verde da Europa"16 o prémio "Folha Verde da Europa"17 e o instrumento "Cidade Verde"18.

14 PUPPIM DE OLIVEIRA, J.A., "The implementation of climate change related policies at the subnational level: an analysis of three countries", Habitat International, Vol. 33, Ed. 3ª, Julho de 2009, pp. 253-259.

15 COMISSÃO EUROPEIA, O reexame da aplicação da política ambiental 2019. Relatório Sobre Portugal. Disponível em: https:// ec.europa.eu/environment/eir/pdf/report_pt_pt.pdf, p. 28.

16 COMISSÃO EUROPEIA, Capital Verde da Europa. Disponível em: https://ec.europa.eu/environment/europeangreencapital/ index_en.htm.

17 COMISSÃO EUROPEIA, Prémio Folha Verde da Europa. Disponivel em: https://ec.europa.eu/environment/europeangreencapital/europeangreenleaf/.

18 COMISSÃO EUROPEIA, Instrumento Cidade Verde. Disponível em: https://webgate.ec.europa.eu/greencitytool/home/. 


\section{Resíduos}

\subsection{Resíduo como recurso}

O Parlamento Europeu, em recente ficha temática sobre a União Europeia ${ }^{19}$, lembrou que todos os produtos têm por base recursos naturais, sendo certo que, caso se mantenham os atuais modelos de utilização dos recursos, a degradação ambiental e a diminuição dos recursos naturais continuarão a avançar, tal como a produção de resíduos. A Europa consome grande quantidade de recursos naturais, deixando em risco recursos escassos. A preocupação com a utilização racional dos recursos naturais consistiu numa das preocupações ambientais incipientes constantes da base dos primeiros Tratados europeus e, atualmente, estão sendo impostas estratégias para diminuição de diminuição de resíduos em aterro e estabelecidas metas de reciclagem e reaproveitamento dos resíduos no intuito de transformar a Europa autossuficiente em termos de recursos. A Comunicação da Comissão Europeia (COM(2015) 614 final) ${ }^{20}$ "Fechar o ciclo - plano de ação da União Europeia para a economia circular", de 2015, veio realçar o empenho e apoio da União Europeia, com o intuito de dinamizar a Economia Circular na Europa. Este pacote prevê propostas legislativas revistas (Proposta sobre os resíduos e um Plano de Ação para a Economia Circular) que confere à Comissão Europeia um mandato concreto nesse sentido (produção; consumo; aprovisionamento responsável de matérias-primas primárias; gestão de resíduos; conversão de resíduos em recursos-matérias-primas secundárias; consumidores; inovação e investimento), prevendo melhoria da gestão dos resíduos; aumento da reciclagem e redução da deposição em aterros.

De acordo com a Agência Europeia do Ambiente ${ }^{21}$, a abordagem da Europa para a gestão eficiente de resíduos tinha como intenção, no passado, apenas questões sanitárias para reduzir os danos à saúde humana, entretanto, hoje, a preocupação europeia abrange, também, o tratamento dos resíduos como um recurso importante para mitigar a captação dos materiais finitos da natureza. O Tratado sobre o Funcionamento da União Europeia, em seu artigo $191^{\circ}$, defende que as políticas da Europa no domínio do ambiente contribuirão para a prossecução da utilização prudente e racional dos recursos naturais, e assim a importância do tratamento dos resíduos como recurso foi ganhando destaque, tanto que a Decisão 1386/2013 do Parlamento Europeu e do Conselho, na publicação do $7 .^{\circ}$ Programa de Ação em Matéria de Ambiente ${ }^{22}$, colocou

19 PARLAMENTO EUROPEU, Eficiência em termos de recursos e economia circular. Disponível em: https://www.europarl.europa. eu/factsheets/pt/sheet/76/eficiencia-em-termos-de-recursos-e-economia-circular.

20 COMISSÃO EUROPEIA, COM(2015) 614 final. Disponivel em: https://eur-lex.europa.eu/legal-content/PT/TXT/HTML/?uri=C ELEX:52015DC0614\&from=EN.

21 AGÊNCIA EUROPEIA DO AMBIENTE, Waste recycling, 2016. Disponivel em: https://www.eea.europa.eu/data-and-maps/ indicators/waste-recycling-1.

22 COMISSÃO EUROPEIA, 70 Programa de ação para o Ambiente da União Europeia para 2020 em matéria de ambiente: "Viver bem, dentro dos limites do nosso planeta". Disponivel em: https://ec.europa.eu/environment/pubs/pdf/factsheets/7eap/ pt.pdf. 
como segundo objetivo temático prioritário "tornar a União uma economia hipocarbónica, eficiente na utilização dos recursos, verde e competitiva". A legislação tem avançado neste sentido, tanto que a nova Diretiva 2018/851 do Parlamento Europeu e do Conselho (que altera a Diretiva 2008/98, relativa aos resíduos), nas considerações iniciais, assim descreve: "A gestão de resíduos na União deverá ser melhorada e transformada em gestão sustentável dos materiais, a fim de proteger, preservar e melhorar a qualidade do ambiente, proteger a saúde humana, assegurar uma utilização prudente, eficiente e racional dos recursos naturais".

O objetivo de transformar resíduos em recursos corresponde ao desenvolvimento e implementação de políticas que auxiliem a transição de uma economia linear para uma economia circular, baseada num modelo de desenvolvimento sustentável que visem assegurar que os resíduos sejam geridos com um recurso e, neste sentido, a Diretiva 2008/98, que orienta a política da Europa em matéria de resíduos, baseia-se na hierarquia de resíduos ( $\operatorname{artigo~} 4^{\circ}$ ), que prioriza a prevenção ou redução de resíduos, seguida pela preparação para a reutilização, reciclagem, outras valorizações e, finalmente, eliminação ou aterro, que é a opção menos desejável. A aplicação da hierarquia supracitada tem como consequência última uma mais eficiente gestão dos resíduos ${ }^{23}$. Neste panorama, cumpre levar em consideração o Roteiro para uma Europa eficiente em termos de recursos (COM(2011) 571), que contém uma seção sobre a transformação de resíduos em recurso e isso se concentra na melhoria da gestão dos resíduos que permitirá utilizar melhor os recursos, desenvolvendo uma combinação de políticas que ajudam a criar uma economia de reciclagem completa.

\subsection{Gestão eficiente de resíduos}

\subsubsection{Questões políticas e legais}

As cidades são núcleos de atração materiais, humanos e financeiros, mas também de produção de emissões e de resíduos. O PNUMA (Programa das Nações Unidas para o Meio Ambiente $)^{24}$ que maioria da população mundial vive em cidades, que concentram $75 \%$ do consumo de recursos naturais e 50\% da produção de resíduos a nível global, sendo responsáveis por 60 a 80\% das emissões dos gases de efeito estufa. Entretanto, como referido anteriormente, as políticas de racionalização na utilização de recursos naturais têm, nas cidades, um grande potencial de sucesso quando há uma recolha e tratamento dos resíduos, de modo a determinar diversos ganhos na intensidade de uso dos recursos naturais ${ }^{25}$.

23 DEPARTMENT FOR ENVIRONMENT, FOOD \& RURAL AFFAIRS, Guidance on applying the Waste Hierarchy. Disponivel em: https://assets.publishing.service.gov.uk/government/uploads/system/uploads/attachment_data/file/69403/pb13530waste-hierarchy-guidance.pdf.

24 ORGANIZAÇÃO DAS NAÇÕES UNIDAS (BRASIL). Disponivel em: https://nacoesunidas.org/ate-2050-serao-necessariostres-planetas-para-suprir-necessidades-da-populacao-mundial-alerta-onu/.

25 DIREÇÃO GERAL DO TERRITÓRIO, Cidades Sustentáveis 2020, DGT, Lisboa, 2015, p. 89. Disponível em: http://www.dgterritorio.pt/ordenamento_e_cidades/cidades/cidades_sustentaveis_2020\%. 
Uma verdadeira agenda de desenvolvimento sustentável de um governo inteligente deve, necessariamente, incluir gerenciamento adequado de resíduos. Para isso, é importante esclarecer as características e tendências globais da região e, portanto, as razões pelas quais essa gestão se torna uma prioridade política e quais são os riscos inerentes à inação. Esse processo deve ser marcado por uma mudança de paradigmas na qual o gerenciamento de resíduos é um participante importante na transição de uma economia linear para uma circular e para o cumprimento dos os Objetivos de Desenvolvimento Sustentável que foram estabelecidos na Agenda 2030, mais especificamente os objetivos 11 e 12.

A Diretiva-Quadro Resíduos (2008/98 CE) foi recentemente alterada por quatro diretivas que determinam novas regras para aumentar os níveis de reciclagem dos resíduos e reduzir a deposição em aterros. As novas regras estão integradas no pacote relativo à Economia Circular ${ }^{26}$, publicado em 2015, e estipulam, em primeiro lugar, que a reciclagem de resíduos urbanos terá de aumentar dos atuais 44\% para: 55\% até 2025; 60\% até 2030 e 65\% até 2035.

Neste seguimento, em maio de 2016, os Ministros dos Estados Membros da União Europeia responsáveis pelo Desenvolvimento Urbano reuniram-se em Amesterdão para adotar a Agenda Urbana para a União Europeia, designada "Pacto de Amesterdão", onde, entre os 12 temas prioritários, destaca-se a Economia Circular, de modo a promover a renovação e a reciclagem dos materiais e dos produtos por meio de políticas urbanas na área de gestão de resíduos.

A política europeia prioriza a problemática dos resíduos urbanos, pois a sua importância ambiental pode potenciar uma gestão mais eficiente dos recursos naturais, reduzindo os impactos ambientais associados à sua utilização. Além disso, os desafios que se colocam na gestão dos resíduos sólidos urbanos ${ }^{27}$ são de nível diferenciado em relação aos demais tipos de resíduos em decorrência dos quantitativos produzidos e da dispersão territorial existente.

É relevante considerar que uma melhor aplicação da legislação existente já traria imensos benefícios para uma gestão eficiente de resíduos. Um estudo elaborado pela Comissão Europeia28, em 2012, previu que a aplicação total da legislação da União Europeia relativa aos resíduos resultaria em poupanças de 72 mil milhões de euros por ano, aumentaria o volume de negócios anual do setor de reciclagem e de gestão de resíduos da Europa em 42 mil milhões de euros e criaria mais de 400000 novos empregos até 2020. Se aplicada de forma correta, a legislação ambiental Europeia cria condições equitativas e oportunidades no mercado único para investimentos

COMISSÃO EUROPEIA, COM(2015) 614 final, plano de ação da UE para a economia circular.

27 De acordo com a Diretiva 2018/851 do PARLAMENTO EUROPEU E DO CONSELHO, os resíduos urbanos são definidos como resíduos das habitações e resíduos de outras origens, tais como comércio de retalho, administração, educação, serviços de saúde, hotelaria e serviços de alimentação, e outros serviços e atividades, que sejam semelhantes em termos de natureza e composição aos resíduos das habitações. Por conseguinte, os resíduos urbanos incluem, nomeadamente, os resíduos da manutenção de parques e jardins, tais como folhas, relva e resíduos da poda de árvores, e os resíduos resultantes dos serviços de limpeza de mercados e ruas, tais como o conteúdo dos contentores de lixo e os resíduos provenientes da varredura das ruas, exceto materiais como areia, pedra, lama ou pó.

28 COMISSÃO EUROPEIA, 70 Programa de ação para o Ambiente da União Europeia para 2020 em matéria de ambiente: "Viver bem, dentro dos limites do nosso planeta". Disponivel em: https://ec.europa.eu/environment/pubs/pdf/factsheets/7eap/ pt.pdf. 
sustentáveis, para além dos benefícios ambientais. A Ciência Jurídica e o Direito é importante para conceber soluções institucionais para as questões urbanas que dialoguem com as novas tecnologias. Entretanto não basta haver normas gerais como as diretivas europeias sobre resíduos e políticas de metas a serem atingidas sem um instrumento de regulação direta de comando e controle, que tem por base normas legais que respondem à fórmula de coerção-sanção legal. Sua importância é fundamental em questões ambientais, pois é a principal forma de intervenção do Estado no controle da execução de certos comportamentos ou o cumprimento de obrigações, sendo certo que a governança na gestão de resíduos encontra um de seus principais pilares nos sistemas legais e nas regras que os geradores e gestores de resíduos devem cumprir, bem como multas aplicáveis a casos de não conformidade (consubstanciando a aplicação do princípio do poluidor-pagador).

Nos serviços públicos, que é o elemento prioritário de uma cidade inteligente, o gerenciamento inteligente de resíduos é um fator chave importante para o desenvolvimento de melhora da qualidade de vida dos cidadãos, porém ainda é um desafio a ser superado para as cidades e comunidades que pretendem ser sustentáveis e inclusivas para todos ${ }^{29}$. A gestão de resíduos na cidade precisa, necessariamente, de um planejamento, que nada mais é do que a aplicação do princípio da prevenção, princípio chave da lei ambiental que obriga a agir diligentemente sobre as causas e as fontes de problemas ambientais, tentando evitar impactos negativos no meio ambiente. O planejamento requer análise prévia de causas que poderiam levar a cenários indesejados e identificar os aspectos que precisam ser levados em consideração para a concretização dos objetivos definidos. Na gestão de resíduos sólidos urbanos, os governos das cidades inteligentes planejam de acordo com as mudanças tecnológicas, com as mudanças e consciência de hábitos e consumo dos cidadãos, e requer o funcionamento de um sistema inspirado na economia de recursos naturais e de baixo carbono. Neste planejamento, é importante ter conhecimento do tipo de resíduo gerado, as quantidades geradas e sua distribuição geográfica, o leque de atores vinculados à gestão, as tecnologias disponíveis, etc. ${ }^{30}$.

\subsubsection{A tecnologia como facilitadora do serviço público de gestão de resíduos urbanos}

A gestão de resíduos sólidos urbanos ${ }^{31}$ é um serviço público que quase todo governo da cidade fornece a seus moradores. Embora os níveis de serviço, os impactos e os custos ambientais variem dramaticamente, o gerenciamento de resíduos sólidos é sem dúvida o serviço municipal mais importante e serve como pré-requisito para outras

29 KAZA, S., YAO, L.C., BHADA-TATA, P. e VAN WOERDEN, F., "What a Waste 2.0: A Global Snapshot of Solid Waste Management to 2050", Urban Development, Banco Mundial, Washington D.C., 2018. Disponivel em: https://openknowledge.worldbank.org/handle/10986/30317.

30 ORGANIZAÇÃO DAS NAÇÕES UNIDAS, Programa das Nações Unidas para o Meio Ambiente: Perspectiva de la Gestión de Residuos en América Latina y el Caribe, 2018, p. 127. Disponível em: https://wedocs.unep.org/bitstream/handle/20.500.11822/26448/Residuos_LAC_ES.pdf?sequence=1\&isAllowed=y.

31 Os resíduos urbanos são constituídos pelos resíduos recolhidos pelas autoridades municipais ou em seu nome, ou diretamente pelo setor privado (empresas ou instituições privadas sem fins lucrativos) não em nome dos municípios. 
ações municipais. Em verdade, uma cidade que não consegue gerenciar, efetivamente, seus resíduos, raramente está hábil para gerenciar serviços mais complexos, como saúde, educação ou transporte ${ }^{32}$. Em poucas palavras, podemos considerar que a gestão de resíduos sólidos urbanos é um conjunto de estratégicas institucionais, legais e financeiras capaz de orientar a organização do setor ${ }^{33}$.

A Diretiva 2018/851 estabelece que a responsabilidade geral pela recolha dos resíduos urbanos é dos municípios (apesar de ser permitido um sistema de gestão de resíduos em que esses serviços são contratados a operadores privados, ou qualquer outro tipo de repartição de responsabilidades entre intervenientes públicos e privados). Ora, a responsabilidade pela execução de sistemas de gerenciamento de resíduos sólidos, na maioria das vezes, recai sobre os governos municipais, que precisam estabelecer regras e regulamentos locais para este fim. Os regulamentos locais cobrem aspectos específicos da gestão de resíduos, incluindo separação de fontes, taxas domésticas e comerciais, locais de descarte, a agências responsáveis pela implementação de operações de resíduos e iniciativas, entre outras ${ }^{34}$. É papel da administração pública dos municípios promover o saneamento e limpeza pública da sua cidade, que inclui a gestão de resíduos sólidos urbanos, tendo como base o ordenamento territorial e o uso do solo, pois todo o resíduo coletado deve ter destino adequado e não pode ser depositado de forma irregular ${ }^{35}$.

Os gestores municipais de resíduos sólidos são responsáveis pela tarefa de remover o "lixo" produzido, mas deve fazê-lo da maneira mais econômica, social e ambientalmente adequada possível, entretanto, é de extrema importância entender que resíduo não é lixo. Sem a intensão de esgotar todos os conteúdos relativos ao tema, resíduos sólidos urbanos são restos de alimentos, embalagens descartadas, objetos inservíveis, etc., que, quando separados por tipos de materiais, são reaproveitados na cadeia de reuso ou reciclagem, não cabendo, a denominação de lixo (que o que não pode ser mais reaproveitado) para aquilo que sobra no processo de produção ou de consumo. A clareza na compreensão desta diferenciação é o que permite avançar na construção de um novo paradigma que supere, inclusive o conceito de limpeza urbana. ${ }^{36}$

Impende destacar que o problema dos resíduos não diz respeito à coleta e ao local de deposição, pois, atualmente, os esforços centram-se no desvio de resíduos urbanos de aterros, a reciclagem e a valorização dos materiais coletados. Quando se trata de entender a importância desta gestão, devemos ter em mente que o gerenciamento de

32 HOORNWEG, D. e BHADA-TATA, P., "Que desperdício: uma revisão global da gestão de resíduos sólidos", Série de desenvolvimento urbano, n. 15, Washington D.C., Banco Mundial, 2012. Disponivel em: https://openknowledge.worldbank.org/handle/10986/17388.

33 LIMA, J.D., Gestão de resíduos sólidos urbanos no Brasil, ABES, Rio de Janeiro, 2001, p. 267.

34 KAZA, S., YAO, L.C., BHADA-TATA, P. e VAN WOERDEN, F., "What a Waste 2.0: A Global Snapshot of Solid Waste Management to 2050", cit., p. 91.

35 O resíduo urbano depositado de forma irregular provoca efeitos negativos nas cidades, tais como assoreamento de rios e córregos, entupimento de vias de escoamento de águas pluviais e consequente inundações em época de chuvas, destruição de áreas verdes, mau cheiro, proliferação de insetos e animais vetores de doenças. REZENDE, D.A. e CASTOR, B.V.J., Planejamento estratégico municipal: empreendedorismo participativo nas cidades, prefeituras e organizações públicas, Ed. 2a , Brasport, Rio de Janeiro, 2006.

36 GRIMBERG, E., A Política Nacional de Resíduos Sólidos: a responsabilidade das empresas e a inclusão social, Instituto Pólis, São Paulo, 2004. 
resíduos urbanos é composto de diferentes estágios, da coleta e transporte ao tratamento. A coleta é o fator chave para alcançar uma gestão tão eficiente dos resíduos urbanos por duas razões: seus custos e seu componente logístico. A recolha de Resíduos Sólidos Urbanos é uma atividade complexa e, em termos econômicos, geralmente é o que mais recursos consomem nos sistemas de limpeza urbana das cidades ${ }^{37}$.

Mais uma vez impende trazer a comento a Diretiva 2018/851, que veio alterar a Diretiva 2008/98 (Diretiva Quadro de Resíduos) em diversas matérias relativas a resíduos, incluindo alterações em matéria de obrigação de recolha seletiva de resíduos urbanos nas frações "material" e biorresíduos. Antes, enquanto meio para assegurar a valorização de resíduos, a recolha seletiva de resíduos era uma recomendação, mas com a atual alteração, a recolha seletiva passou a ser uma obrigação. Contudo, foram previstos alguns cenários, de natureza técnica, ambiental e económica, em que é admissível que se concedam derrogações à obrigação de recolha seletiva.

Os resíduos sólidos urbanos coletados podem ser separados ou misturados, dependendo dos regulamentos locais. Enquanto a maioria dos resíduos reciclados é coletada separadamente, outra parte vem da extração de materiais recicláveis de resíduos municipais misturados em plantas de pré-tratamento. Isso geralmente resulta em materiais reciclados de menor qualidade e pode aumentar o risco de contaminação dos ciclos dos materiais e do meio ambiente ${ }^{38}$. A separação dos resíduos na fonte pode adicionar custos ao processo de coleta do lixo, mas, por outro lado, há ganhos ambientais e cumprimentos das metas e da legislação europeia para o setor dos resíduos no que tange à reciclagem e deposição em aterros.

Mas como chegar às metas de sustentabilidade no setor dos resíduos? É aí que entram as tecnologias utilizadas pelas cidades inteligentes para tratamento e reciclagem dos resíduos urbanos. A tecnologia ajuda a ter uma visão sistêmica do processo, desde a prevenção durante a fase de geração, até o reaproveitamento, passando pela coleta, transporte, tratamento mais adequado a cada tipo de resíduo. Entre as soluções mais comumente empregadas estão reservatórios subterrâneos com sensores que avisam quando estão chegando ao limite para que os resíduos ali depositados sejam removidos, a recolha seletiva, reciclagem e a transformação dos resíduos orgânicos e do metano em energia (gás) 39.

Um exemplo de sucesso do uso da tecnologia para gestão de resíduos urbanos é a cidade de Santander. Em Santander, a recolha seletiva dos resíduos sólidos é automatizada. Os contentores públicos informam quando estão cheios, evitando a recolha quando ainda é desnecessária. O projeto, desenvolvido em parceria com a Universidade de Cantábria, envolve a implantação de uma solução de tecnologia que inclui sensores de volume, umidade, odor e emissão de gases, entre outros, presentes nos contentores,

37 ORGANIZAÇÃO DAS NAÇÕES UNIDAS, Programa das Nações Unidas para o Meio Ambiente: Perspectiva de la Gestión de Residuos en América Latina y el Caribe, 2018, p. 127. Disponivel em: https://wedocs.unep.org/bitstream/handle/20.500.11822/26448/Residuos_LAC_ES.pdf?sequence=1\&isAllowed=y.

38 AGÊNCIA EUROPEIA DO AMBIENTE, Recycling of municipal waste. Disponivel em: https://www.eea.europa.eu/airs/2018/ resource-efficiency-and-low-carbon-economy/recycling-of-municipal-waste.

39 BOUSKELA, M., CASSEB, M., BASSI, S., DE LUCA, C. e FACCHINA, M., Caminho para as smart cities: Da gestão tradicional para a cidade inteligente, Banco Interamericano de Desenvolvimento, Washington D.C., 2016, p. 93. 
aplicações móveis para auxiliar o trabalho de recolha e manutenção, sendo certo que o conjunto dessas infraestruturas permite a análise em tempo real dos dados coletados e é, hoje, a principal ferramenta para tomada de decisão das empresas de gestão de resíduos sólidos urbanos. Cumpre destacar que a iniciativa tecnológica conta também com a participação ativa dos cidadãos, que através de uma aplicação no telemóvel, podem identificar áreas que precisam de atendimento e limpeza e enviar alertas aos responsáveis pela gestão dos resíduos urbanos. Este modelo automatizado de gestão de resíduos confere benefícios ambientais à cidade, pois reduz a emissão de gás carbônico a partir da economia de combustível obtida com a otimização das rotas de recolha, reduz os gastos de hora de trabalho (capital humano), motiva os cidadãos para separação dos resíduos com o fim de reciclagem e a previne doenças provocadas por vetores ao evitar a saturação dos contentores.

\section{Conclusão}

Os territórios inteligentes promovem qualidade de vida para os cidadãos qua lá vivem por meio de melhorias nos serviços públicos e implementação de tecnologias. Uma cidade inteligente também constitui ser sustentável quando reduz a produção de resíduos, o consumo de recursos, promove uma utilização mais sustentável da água, reduz a poluição do ar e da água e melhora a mobilidade urbana.

A União Europeia é dependente de recursos materiais para quase todas as suas atividades, mas a extração destes recursos tem impactos significativos no ambiente, bem como na economia, torna-se cada vez mais essencial reutilizar esses materiais e mantê-los por períodos mais longos, de modo a reduzir a necessidade de usar materiais virgens. Os territórios inteligentes devem incrementar a eficiência do metabolismo urbano, assumindo a prioridade de redução e valorização do resíduo como um recurso, ampliando o quadro de soluções de reutilização, reciclagem e valorização dos resíduos urbanos.

AAgência Europeia do Ambiente, no Relatório sobre Recursos e Gestão de Resíduos ${ }^{40}$, publicado em 28/10/2019, revela que está a haver uma evolução na Europa no sentido de melhorar uma já ambiciosa política de resíduos, entretanto União Europeia continua a perder oportunidades para reutilizar recursos valiosos que estão a perder-se através de práticas ineficientes de gestão de resíduos.

Para tornar os resíduos em recurso, os governos dos territórios inteligentes precisam aplicar integralmente a legislação da União Europeia em matéria de resíduos, o que inclui a hierarquia dos resíduos, a necessidade de uma recolha seletiva de resíduos, o cumprimento dos objetivos de eliminar gradualmente a deposição em aterro de resíduos recicláveis ou recuperáveis. Cumpre, entretanto, às cidades, introduzir novos instrumentos políticos, nomeadamente instrumentos financeiros, para promover a prevenção e tornar a reciclagem economicamente mais atrativas, melhorar e alargar

$40 \quad$ AGÊNCIA EUROPEIA DO AMBIENTE, Resource efficiency and waste "Waste management". Reducing loss of resources from waste management is key to strengthening the circular economy in Europe. Disponivel em: https://www.eea.europa.eu/publications/reducing-loss-of-resources-from. 
a recolha seletiva de resíduos, implementar sistemas de pagamento em função da produção de resíduos (como o sistema PAYT - pay as you throw), bem como serviços de recolha porta a porta ${ }^{41}$.

Neste contexto, as políticas e os sistemas de gestão de resíduos devem implementar estratégias públicas apropriadas, com marcos regulatórios, utilização de tecnologias disponíveis e formas de educação e comunicação que contribuam para a sustentabilidade.

\section{Bibliografia}

AGÊNCIA EUROPEIA DO AMBIENTE, Resource efficiency and waste "Waste management". Reducing loss of resources from waste management is key to strengthening the circular economy in Europe. Disponivel em: https://www.eea.europa.eu/ publications/reducing-loss-of-resources-from.

AGÊNCIA EUROPEIA DO AMBIENTE, Waste recycling, 2016. Disponível em: https:// www.eea.europa.eu/data-and-maps/indicators/waste-recycling-1.

AGÊNCIAEUROPEIADO AMBIENTE, Recycling of municipal waste. Disponível em: https:// www.eea.europa.eu/airs/2018/resource-efficiency-and-low-carbon-economy/ recycling-of-municipal-waste.

BOUSKELA, M., CASSEB, M., BASSI, S., DE LUCA, C. e FACCHINA, M., Caminho para as smart cities: Da gestão tradicional para a cidade inteligente, Banco Interamericano de Desenvolvimento, Washington D.C., 2016.

CAPDEVILA, J. e ZARLENGA, M.I., "Smart city or smart citizens? The Barcelona case", Journal of Strategy and Management, n. 8(3), 2015. Disponível em: https://www. researchgate.net/publication/277180909_Smart_City_or_smart_citizens_ The_Barcelona_case (Consultado em outubro de 2019).

COMISSÃO EUROPEIA, $7^{\circ}$ Programa de ação para o Ambiente da União Europeia para 2020 em matéria de ambiente: "Viver bem, dentro dos limites do nosso planeta". Disponível em: https://ec.europa.eu/environment/pubs/pdf/factsheets/7eap/ pt.pdf.

COMISSÃO EUROPEIA. Disponível em: http://ec.europa.eu/eip/smartcities/ (Consultado em outubro de 2019).

COMISSÃO EUROPEIA, O reexame da aplicação da política ambiental 2019. Relatório sobre Portugal. Disponível em: https://ec.europa.eu/environment/eir/pdf/ report_pt_pt.pdf.

COMISSÃO EUROPEIA, Capital Verde da Europa. Disponível em: https://ec.europa.eu/ environment/europeangreencapital/index_en.htm.

COMISSÃO EUROPEIA, Prémio Folha Verde da Europa. Disponível em: https://ec.europa. eu/environment/europeangreencapital/europeangreenleaf/.

COMISSÃO EUROPEIA, Instrumento Cidade Verde. Disponível em: https://webgate. ec.europa.eu/greencitytool/home/.

COMISSÃO EUROPEIA, O reexame da aplicação da política ambiental 2019. Relatório sobre Portugal, p. 10. Disponível em: https://ec.europa.eu/environment/eir/pdf/report_pt_pt.pdf. 
COMISSÃO EUROPEIA, COM(2015) 614 final. Disponível em: https://eur-lex.europa. eu/legal-content/PT/TXT/HTML/?uri=CELEX:52015DC0614\&from=EN.

COMISSÃO EUROPEIA, O reexame da aplicação da política ambiental 2019. Relatório Sobre Portugal. Disponível em: https://ec.europa.eu/environment/eir/pdf/ report_pt_pt.pdf.

DEPARTMENT FOR ENVIRONMENT, FOOD \& RURAL AFFAIRS, Guidance on applying the Waste Hierarchy. Disponível em: https://assets.publishing.service.gov.uk/ government/uploads/system/uploads/attachment_data/file/69403/pb13530waste-hierarchy-guidance.pdf.

DIREÇÃO GERAL DO TERRITÓRIO, Cidades Sustentáveis 202o, DGT, Lisboa, 2015. Disponível em: http://www.dgterritorio.pt/ordenamento_e_cidades/cidades/ cidades_sustentaveis_2020/.

GRIMBERG, E., A Política Nacional de Resíduos Sólidos: a responsabilidade das empresas e a inclusão social, Instituto Pólis, São Paulo, 2004.

GOVERNO PORTUGUÊS, Resolução do Conselho de Ministros n. 61/2015 de 11 de agosto. Disponível em: https://dre.pt/application/file/69977523.

HOORNWEG, D. e BHADA-TATA, P., "Que desperdício: uma revisão global da gestão de resíduos sólidos”, Série de desenvolvimento urbano, n. 15, Washington D.C., Banco Mundial, 2012. Disponível em: https://openknowledge.worldbank.org/ handle/10986/17388.

KAZA, S., YAO, L.C., BHADA-TATA, P. e VAN WOERDEN, F., "What a Waste 2.o: A Global Snapshot of Solid Waste Management to 2050", Urban Development, Banco Mundial, Washington D.C., 2018. Disponível em: https://openknowledge. worldbank.org/handle/10986/30317.

LIMA, J.D., Gestão de resíduos sólidos urbanos no Brasil, ABES, Rio de Janeiro, 2001.

MACENA, J.P., "Munícipios 4.0 aborda tecnologias que proporcionam melhorias em serviços públicos", Agência Sebrae de Notícias, Alagoas, 2019. Disponível em: http://www.al.agenciasebrae.com.br/sites/asn/uf/AL/municipios40-aborda-tecnologias-que-proporcionam-melhorias-em-servicospublicos,71a2d13eb23fc610VgnVCM1000004C00210aRCRD_(Consultado em outubro de 2019).

ORGANIZAÇÃO DAS NAÇÕES UNIDAS, Programa das Nações Unidas para o Meio Ambiente: Perspectiva de la Gestión de Residuos en América Latina y el Caribe, 2018. Disponível em: https://wedocs.unep.org/bitstream/handle/20.500.11822/26448/ Residuos_LAC_ES.pdf?sequence=1\&isAllowed=y.

PARLAMENTO EUROPEU, Eficiência em termos de recursos e economia circular. Disponível em: https://www.europarl.europa.eu/factsheets/pt/sheet/76/ eficiencia-em-termos-de-recursos-e-economia-circular.

PHILIPPI, JR.A. e MALHEIROS, T.F., "Saneamento e saúde pública: integrando Homem e Ambiente", Alves, A.C. e Philippi, JR.A. (eds.), Curso Interdisciplinar de Direito Ambiental, Manole, São Paulo, 2005. 
PUPPIM DE OLIVEIRA, J.A., "The implementation of climate change related policies at the subnational level: an analysis of three countries", Habitat International, Vol. 33, Ed. $3^{\text {a }}$, Julho de 2009.

REVISTA SMART CITIES. Disponível em: http://smart-cities.pt/revista-smart-cities/. (Consultado em outubro de 2019).

REZENDE, D.A. e CASTOR, B.V.J., Planejamento estratégico municipal: empreendedorismo participativo nas cidades, prefeituras e organizações públicas, Ed. $2^{\mathrm{a}}$, Brasport, Rio de Janeiro, 2006.

UNITED NATIONS ENVIRONMENT PROGRAMME (UNEP) e UNITED NATIONS INSTITUTE FOR TRAINING AND RESEARCH (UNITAR), Study Guidelines for National Waste Management Strategies: Moving from Challenges to Opportunities. Disponível em: http://cwm.unitar.org/national-profiles/publications/cw/wm/ UNEP_UNITAR_NWMS_English.pdf (Consultado em outubro de 2019). 